\title{
Chairman's introduction
}

Welcome to the symposium on 'Enzyme Assays in Medicine' planned by the Committee on Chemical Pathology of the Association of Clinical Pathologists, and in particular by its secretary, Dr Glyn Walters, who has done all the detailed work of organization. We are also indebted to Professor Henry Wilkinson for his advice on subjects and speakers. The intention has been to offer to biochemists, pathologists, and clinicians a picture of present views and possible future progress concerning the biochemical background of clinical enzymology, and the use of enzyme assays in present-day medicine.

Enzymes play a major role in modern biochemistry and medicine, but it is little known that their discovery antedated the idea of non-organic catalysis. It was in the early 1830s that both amylase (from malt) and pepsin (from stomach) were extracted and their properties studied; when the idea of chemical catalysis was put forward in the late 1830s this was based on the known actions of the biological enzymes. The name 'enzyme' was not itself invented until 1878. By the end of these two days we shall have heard the word often enough.

Some enzyme assays which are still valuable for medical diagnosis, such as serum amylase and alkaline phosphatase, have been in use since about 1930. The great increase in popularity of the diagnostic use of enzymes has come since the introduction of the assays of transaminases ${ }^{1}$ and of lactate dehydrogenase in 1954-1955, and the number and types of these tests performed in the general laboratory have continued to grow. At the Royal Free Hospital, London, for example, in 1964 we performed 10 different types of clinical enzyme assay, and of the main ones-alkaline phosphatase and aspartate transaminase-about 4,000 each in the year. Now, in 1970, we assay 17 different enzymes, including about 6,000 assays each of the two main enzymes, a $50 \%$ increase in six years. Enzyme assays make up about $15 \%$ of the total number of tests going through our routine laboratories, and this does not include any biochemical screening or multichannel analyses. Are we doing too many or too few enzyme tests? It is perhaps an appropriate time for this group of experts to come together in order to summarize and discuss the position.

In two days it is impossible to cover the whole of clinical enzymology in detail, and each member of the audience will have his own regrets over topics which have been omitted. I'personally regret the absence of a paper on the use of enzymes as markers in studies of differential urinary protein excretion, and of one on the value of enzyme assays in leucocytes and platelets.

We have tried to arrange the programme so that the more chemical papers are on the first day and the more clinical papers are on the second day. Those of the audience whose interests are wholly on one or other side of enzymology can therefore plan their attendance, though we would all be happy if everyone could stay throughout the meeting, and receive full value for the fees paid by their department.

D. N. BARON

${ }^{1}$ Professor Baron used, and prefers to use, the name 'transaminase'. 